\title{
The Effect of Soybean Trade between China and the United States on Chinese Residents' Consumption Expenditure-Based on 2004-2016 Trade Data
}

\author{
Yangyang $\mathbf{Q} \mathbf{i}^{1}$, Quanlong $\mathbf{Q} \mathbf{i}^{2}$ \\ ${ }^{1}$ Jinan University, Guangdong, China \\ ${ }^{2}$ Institute of Economy, Jinan University, Guangzhou, China \\ Email: 1216727279@qq.com
}

How to cite this paper: Qi, Y.Y. and Qi, Q.L. (2018) The Effect of Soybean Trade between China and the United States on Chinese Residents' Consumption Expenditure-Based on 2004-2016 Trade Data. Modern Economy, 9, 1045-1053.

https://doi.org/10.4236/me.2018.96067

Received: April 23, 2018

Accepted: June 2, 2018

Published: June 5, 2018

Copyright $\odot 2018$ by author and Scientific Research Publishing Inc. This work is licensed under the Creative Commons Attribution International License (CC BY 4.0). http://creativecommons.org/licenses/by/4.0/

\begin{abstract}
This paper uses cointegration analysis method to estimate the correlation between China's per-capita consumption expenditure and the amount of soybean imported from the United States. It is found that importing soy from the United States can reduce China's per capita consumption expenditure. There is a long-term equilibrium between the per capita consumption expenditure and the imports of soybean native to the United States. In the short term, one of them can have a lasting impact on the other.
\end{abstract}

\section{Keywords}

Cointegration Analysis, VECM Model, Per Capita Consumer Expenditure, Impulse Response

\section{Introduction}

The supply of agricultural products has always been the basis for the survival of a country, and it is an important issue related to the national economy and the people's livelihood. In order to release agricultural resources and make up for the shortage of domestic agricultural products, a country will generally choose the import strategy to solve this problem. However, this strategy may make the domestic agricultural product market excessively dependent on the international market, the country lacks independence, and it will seriously cause the country to lack the right to speak. In recent years, China's imports of agricultural products have continued to increase; with soybean imports occupying a more important 


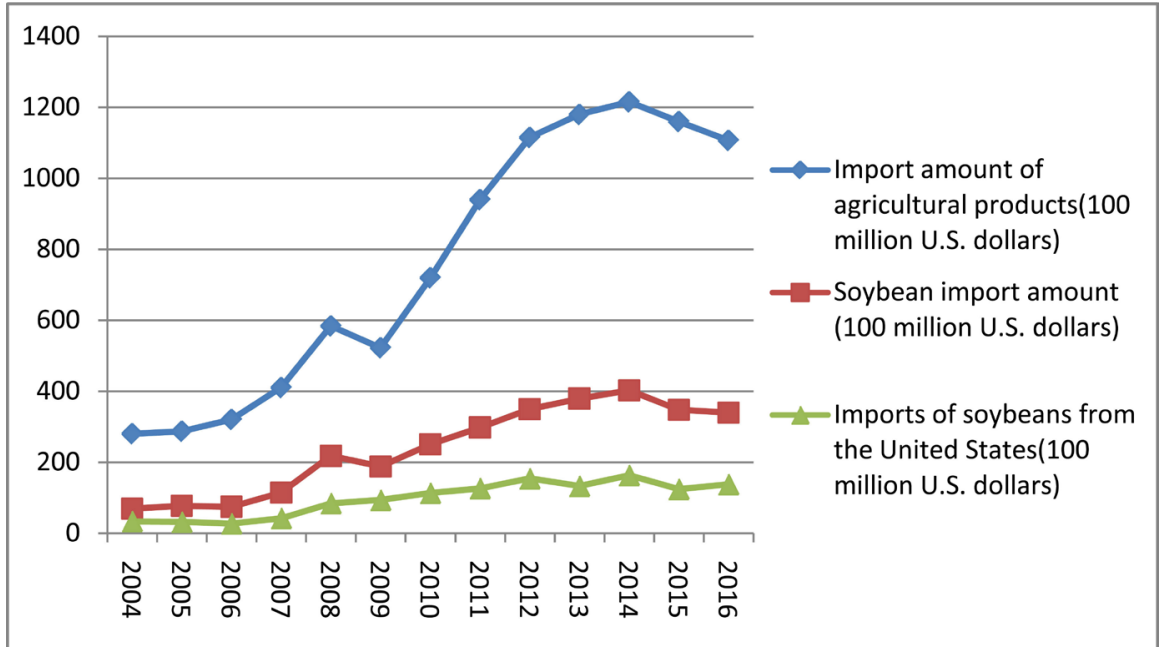

Note: The data comes from the department of foreign trade of the ministry of commerce.

Figure 1. Soybean import data of China.

position (specific details please refer to Figure 1). Therefore, the issue of soybean imports has attracted the attention of many scholars, and they have carried out various researches and analyses on it. With the release of the Ministry of Commerce of the People's Republic of China in 2018 to respond to the international environment, an announcement will be made to impose tariff levies on soy and other agricultural products originating in the United States. This led the public to doubt that the United States has always been one of the major sources of soybean imports in China. Does raising the tariff raise the cost of living?

This paper will adopt a cointegration analysis model to empirically analyze the impact of soybean originating in the United States on the level of Chinese residents' consumption.

\section{Literature Review}

Most studies on soybean import and export at home and abroad have focused on prices (He Lei [1]). Ma Shuzhong and Wang Jun [2] used the PTM model to analyze China's impact on the international soybean market price and found that China is still the recipient of international market prices, the international soybean market price has a greater impact on China's economy, and China's ability to evade the risks of the international soybean market is poor. Qin Yueming [3] used relevant data from 1986 to 2008 to analyze the cointegration test and Granger causality test model and found that the export price of soybean in the United States has a certain guiding effect on the domestic soybean market price in China. Wang Ying [4] used a multiple linear regression method to analyze China and the United States soybean trade data from 2005 to 2009 and believed that the performance of the exchange rate had a certain impact on imports. Chen Yongfu [5] found that China's soybean import and export trade and soybean-related products affect each other. Wei Chen, Mary A. Marchant and Andrew Muhammad [6] found that China's soybean imports were affected by seasonal 
factors, and there was competition between soybean origins in the Chinese market.

\section{Empirical Analysis}

\subsection{Data Description and Selection}

This paper uses the mixed time series data from the China Statistical Yearbook and Ministry of Foreign Affairs of the People's Republic of China for econometric analysis. Because the large difference between the data values of selected indicators, this paper performs logarithmic processing on the selected indicator data. The data on soybean imports originating in the United States and other countries comes from the Department of Foreign Trade, the Ministry of Commerce, and the consumer expenditure of the residents comes from the China Statistical Yearbook. The statistical description of relevant research variables can be seen in Table 1. The difference between the original data variables is large, which is not conducive to statistical analysis; and after the logarithmic processing operations, the differences between variables are reduced, and the data is concentrated in 8-16. This makes research and analysis more convenient. This article uses the resident consumer index to indicate the impact of the source country and amount of soybean imports on the lives of Chinese residents as the dependent variable of the study; the relevant indicator for the amount of soybean imports is used as the independent variable of the study. At the same time, due to the availability of data, this paper adopts 2004-2016 data for empirical analysis.

\subsection{Unit Root Test}

In this paper, the unit root test is conducted on the logarithmic variables of household consumption expenditure, soybean import amount, soybean export amount originating in the United States, and soybean import amount originating in other countries to analyze its stability. The test results are shown in Table 2. From the results, it can be seen that all the original sequences of the variables

Table 1. Statistical description of data variables.

\begin{tabular}{cccccc}
\hline Variable & Mean & Sd. & p50 & Min & Max \\
\hline allconsumption & 12,036 & 5433 & 10,919 & 5138 & 21,228 \\
beanimport & $2.400 \mathrm{e}+06$ & $1.200 \mathrm{e}+06$ & $2.500 \mathrm{e}+06$ & 700,000 & $4.000 \mathrm{e}+06$ \\
usabeanimportt & 970,000 & 490,000 & $1.100 \mathrm{e}+06$ & 270,000 & $1.600 \mathrm{e}+06$ \\
beanimportother & $1.400 \mathrm{e}+06$ & 770,000 & $1.400 \mathrm{e}+06$ & 360,000 & $2.500 \mathrm{e}+06$ \\
lnallconsumption & 9.290 & 0.480 & 9.300 & 8.540 & 9.960 \\
lnbeanimport & 14.52 & 0.660 & 14.73 & 13.46 & 15.21 \\
lnusabeanimport & 13.62 & 0.660 & 13.94 & 12.51 & 14.31 \\
lnbeanimportother & 13.99 & 0.680 & 14.13 & 12.80 & 14.72 \\
\hline
\end{tabular}

Note: The data comes from the china statistical yearbook and ministry of foreign affairs of the people's republic of China. 
are not stable at a significant level of $5 \%$. After a first-order differential, it is significant at a $5 \%$ significant level.

\subsection{Cointegration Test}

The stationarity test shows that all research variables are first-order single integers, then the following will perform further cointegration tests on lnallconsumption, lnbeanimport and lnusabeanimport.

The test results in Table 3 indicate that both model (1) and model (2) are at a significant level of $5 \%$, and there is a unique cointegration equation among the variables, which has a long-term equilibrium relationship. According to the test results and the sample size of the optimal lag period in the 11th model, the two test equations in this paper adopt the regression of the second-order lag. After normalizing the equation, you get:

Table 2. ADF test results.

\begin{tabular}{|c|c|c|c|c|c|}
\hline \multirow[b]{2}{*}{ Variable } & \multirow[b]{2}{*}{ Test Statistic } & \multicolumn{3}{|c|}{ T Statistics } & \multirow[b]{2}{*}{ Test result } \\
\hline & & $\begin{array}{l}\text { Inspection } \\
\text { type }(\mathrm{c}, \mathrm{t}, \mathrm{k})\end{array}$ & $\begin{array}{c}1 \% \text { Critical } \\
\text { value }\end{array}$ & $\begin{array}{c}5 \% \text { Critical } \\
\text { value }\end{array}$ & \\
\hline lnallconsumption & -1.000 & $(c, t, 1)$ & -4.380 & -3.600 & Not smooth \\
\hline$\Delta$ lnallconsumption ${ }^{\star}$ & -3.997 & $(c, t, 1)$ & -4.380 & -3.600 & Smooth \\
\hline lnbeanimport & -0.638 & $(c, t, 1)$ & -4.380 & -3.600 & Not smooth \\
\hline$\Delta \operatorname{lnbeanimport}{ }^{* *}$ & -4.712 & $(c, t, 1)$ & -4.380 & -3.600 & Smooth \\
\hline lnbeanimportother & -0.585 & $(c, t, 1)$ & -4.380 & -3.600 & Not smooth \\
\hline$\Delta$ lnbeanimportother ${ }^{*}$ & -4.214 & $(c, t, 1)$ & -4.380 & -3.600 & Smooth \\
\hline lnusabeanimport & -1.150 & $(c, t, 1)$ & -4.380 & -3.600 & Not smooth \\
\hline$\Delta \operatorname{lnusabeanimport}{ }^{\star}$ & -3.944 & $(c, t, 1)$ & -4.380 & -3.600 & Smooth \\
\hline
\end{tabular}

Note: The data comes from the China Statistical Yearbook and Ministry of Foreign Affairs of the People's Republic of China. ${ }^{*}$ indicates significant at the $1 \%$ level; ${ }^{*}$ indicates significant at the $5 \%$ level; c indicates the constant term, $\mathrm{t}$ indicates the band trend term, and $\mathrm{k}$ indicates the lag order.

Table 3. Johansen trace test results.

\begin{tabular}{cccccc}
\hline Assumptions & Value & Trace statistic & 5\% Critical value & Max statistic & 5\% Critical value \\
None & 0 & 43.0575 & 34.55 & 27.6646 & 23.78 \\
(1) At most 1 & 0.91913 & $15.3930^{*}$ & 18.17 & 14.4355 & 16.87 \\
At most 2 & 0.73081 & 0.9574 & 3.74 & 0.9574 & 3.74 \\
None & 0 & 42.6351 & 34.55 & 27.3430 & 23.78 \\
(2) At most 1 & 0.91673 & $15.2921^{*}$ & 18.17 & 14.1869 & 16.87 \\
At most 2 & 0.72465 & 1.1052 & 3.74 & 1.1052 & 3.74 \\
\hline
\end{tabular}

Note: The data comes from the China Statistical Yearbook and Ministry of Foreign Affairs of the People's Republic of China. ${ }^{*}$ indicates that at a $5 \%$ significance level, it is assumed that there is more than 1 linearly irrelevant cointegration vector. 
lnallconsumption $=-2.8644+2.57371$ lnbeanimport -1.8956 lnusabeanimport

$$
P: \quad 0.000 \quad 0.000
$$

lnallconsumption $=-0.8221+1.5020$ lnbeanimportother -0.8233 lnusabeanimport

$$
P: \quad 0.000 \quad 0.000
$$

The results show that the soybean import amount will have a significant positive impact on China's consumer spending. This may be related to a variety of reasons. Such as: The increase in soybean imports will release the labor force, promote the development of other industries, and increase the consumption expenditure of residents with income; With the development of technology industry, the number and varieties of soybean products have increased, and imported soybeans can just make up for the rising consumption of soybeans in China. $\mathrm{T}$ The impact of soybean imports originating in the United States on consumer spending was significantly negative, indicating that imports of soybeans originating from the United States reduced China's per capita consumer spending, possibly because of the relatively low import prices of US soybeans. As a result, residents' total consumption expenditures have been reduced with constant soybean consumption.

\subsection{VECM System Stability Test}

In order to ensure the rigor and validity of the model, we use AR root test to test the stability of model (1) and model (2). The AR root test is only a method used to check the stability of the system. When the eigenvalue is greater than 1 , the system is unstable; otherwise, the system is stable. The details of the AR root stability test eigenvalue data in this paper are shown in Table 4: The eigenvalues of the two models are not greater than 1, i.e., no eigenvalue falls outside the unit circle, and the overall stability of the VECM (1) and (2) models. In order to observe the analysis results more intuitively, this article also shows the results of the judgment through graphic methods, as shown in Figure 2 and Figure 3.

\subsection{Impulse Response Function}

In order to further examine the relationship between soybean imports and per

\begin{tabular}{|c|c|c|c|c|c|c|c|}
\hline \multicolumn{4}{|c|}{ Model (1) } & \multicolumn{4}{|c|}{ Model (2) } \\
\hline \multicolumn{3}{|c|}{ Eigenvalue } & \multirow{2}{*}{$\begin{array}{c}\text { Modulus } \\
1\end{array}$} & \multicolumn{3}{|c|}{ Eigenvalue } & \multirow{2}{*}{$\begin{array}{c}\text { Modulus } \\
1\end{array}$} \\
\hline & 1 & & & 1 & & & \\
\hline 1 & & & 1 & 1 & & & 1 \\
\hline-0.4859498 & + & $0.1163161 \mathrm{i}$ & 0.499677 & -0.5372443 & & & 0.537244 \\
\hline-0.4859498 & - & $0.1163161 \mathrm{i}$ & 0.499677 & 0.1208636 & + & $0.3661215 \mathrm{i}$ & 0.385555 \\
\hline 0.1543682 & + & $0.3548764 \mathrm{i}$ & 0.386997 & 0.1208636 & - & $0.3661215 \mathrm{i}$ & 0.385555 \\
\hline 0.1543682 & - & $0.3548764 \mathrm{i}$ & 0.386997 & -0.3474429 & & & 0.347443 \\
\hline
\end{tabular}

Table 4. Eigenvalue stability condition.

Note: The data comes from the china statistical yearbook and ministry of foreign affairs of the people's republic of China. 


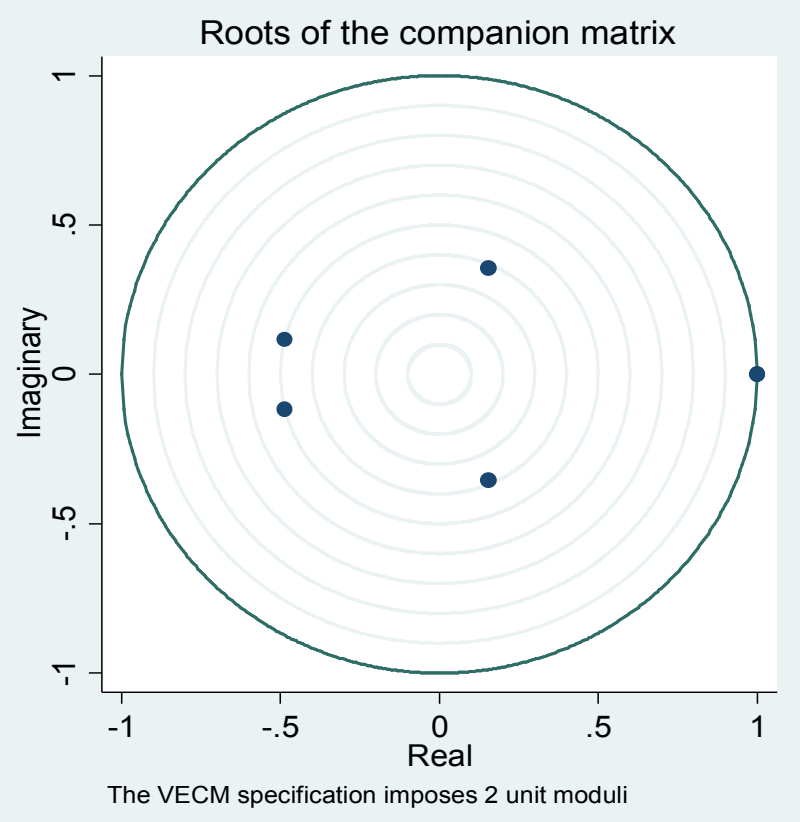

Figure 2. Stability discrimination chart (1).

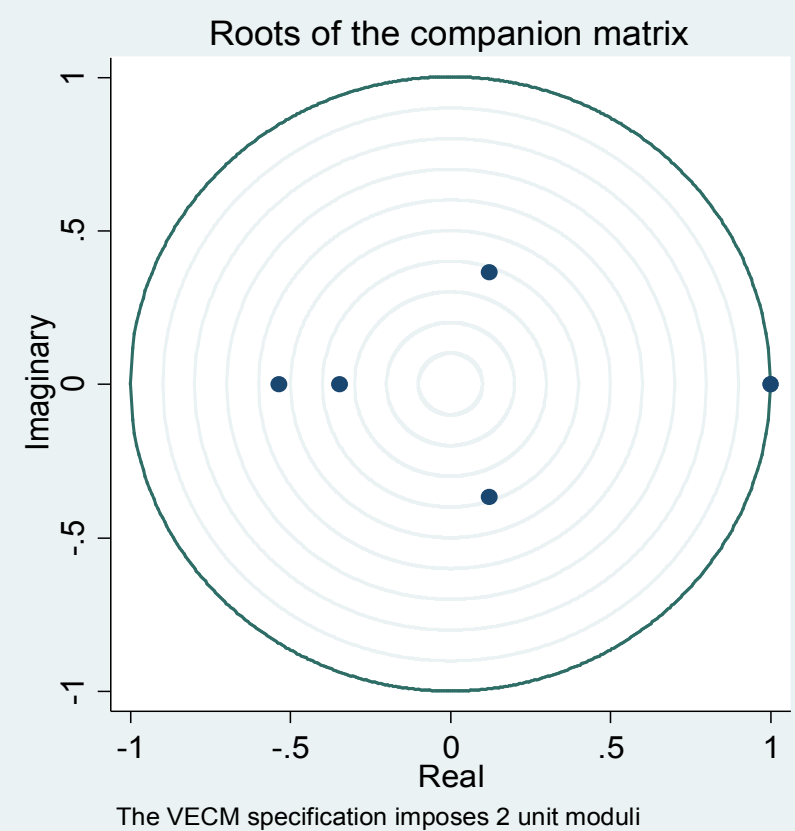

Figure 3. Stability discrimination chart (2).

capita consumer spending, the study period is set to 13 periods, and the use of impulse response function is further explored. Taking Figure 4 as an example, the line graph on the left side of Figure 4 is represented as follows: the relation chart between consumption expenditure as impulse variable and consumer expenditure as the response variable, the relation chart between soybean import amount as impulse variable and consumer expenditure as the response variable, 

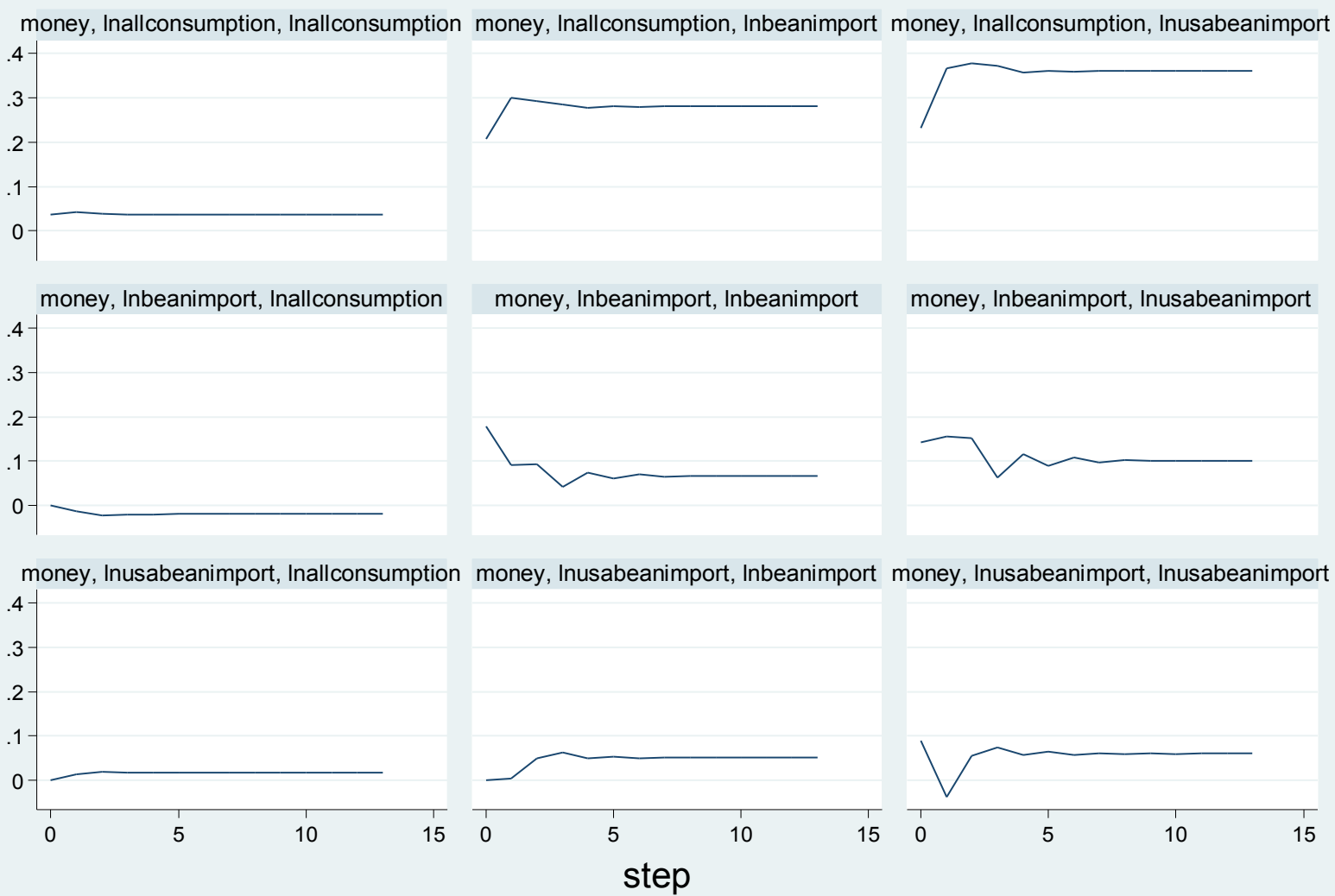

Graphs by irfname, impulse variable, and response variable

Figure 4. Impulse response diagram (1).

and the relation chart between the amount of soybean imported from the United States as impulse variable and consumer expenditure as the response variable. The three line graphs on the left represent the effects of fluctuations in consumer spending, soybean imports, and soybean imports from the United States on consumer spending in China. As can be seen from the figure, the impact of these three factors will cause certain volatility in consumer spending in a short period of time, after which the influence tends to be stable. In the same way, the line graph in Figure 5 also reflects that the impact of soybean imports from the United States will have a lasting effect on consumer spending. First of all, soybeans are used in many fields in China: food, breeding, medicine, industry, etc. They have a wide range of uses and large amounts; China has a long history of soybean use and soybeans have a certain viscosity effect on Chinese consumers. Moreover, the large number of Chinese soybeans imported from the United States will certainly have a certain influence on the Chinese soybean market.

\section{Conclusions and Prospects}

\subsection{The Conclusion}

There is a unique long-term equilibrium relationship between per capita consumption expenditure, soybean import amount, and soybean import amount originating 

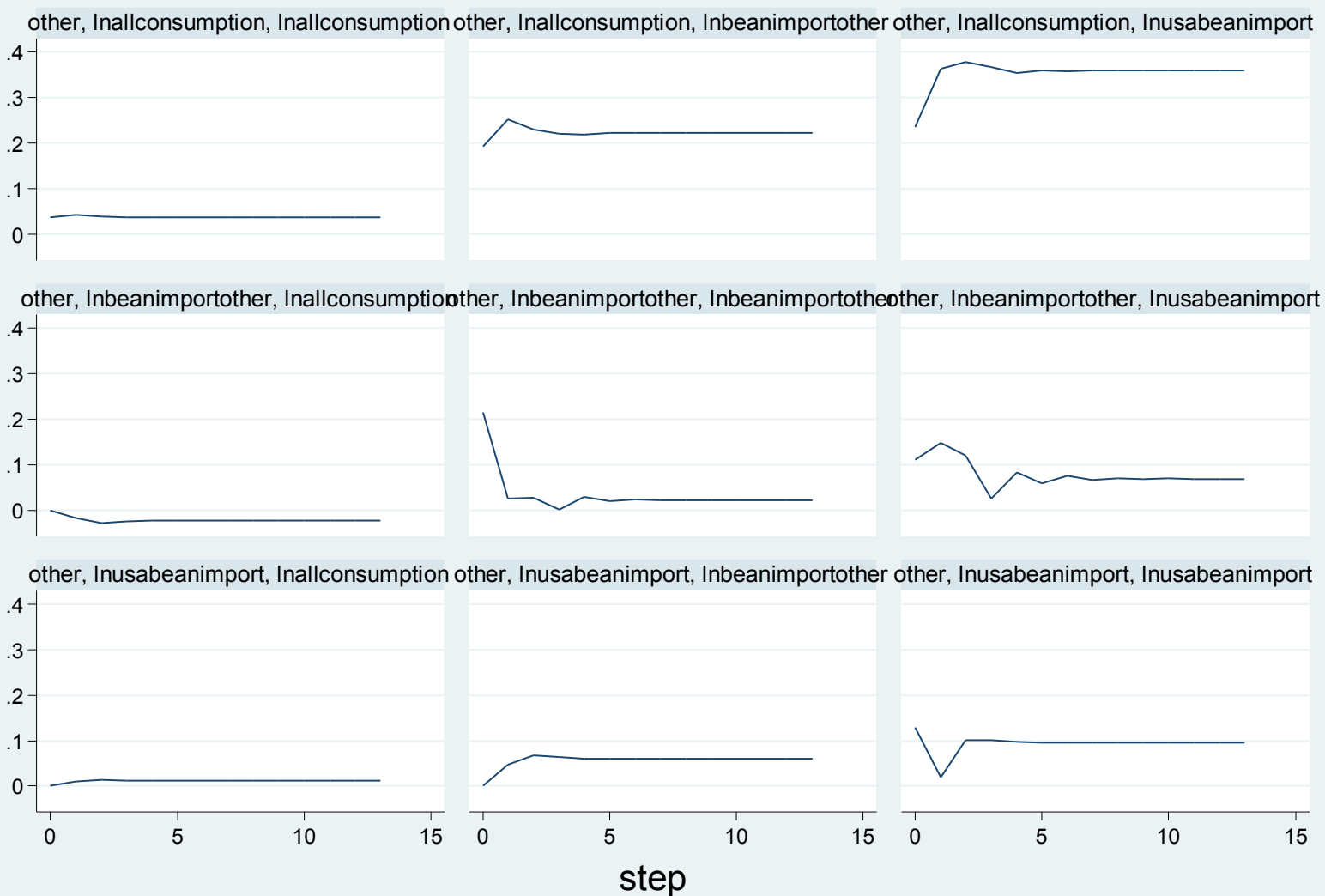

Graphs by irfname, impulse variable, and response variable

Figure 5. Impulse response diagram (2).

in the United States, as well as the per capita consumption expenditure, the amount of soybean originating in other regions, and the amount of soybean originating in the United States. The amount of soybean imports originating in the United States can reduce consumer spending in the long run and significantly increase the consumption level of residents, namely: When the total amount of China's soybean imports does not change, a $1 \%$ increase in the amount of soybean imports originating in the United States will cause a decrease of $1.8956 \%$ in per capita consumer spending. When the amount of soybean imported from other regions is constant, a $1 \%$ increase in the amount of soybean imports originating in the United States will cause a per capita consumption expenditure decrease of $0.8233 \%$.

Second, in the short term, the amount of soybean imports originating in the United States can form an effective and lasting positive impact on per capita consumer spending. In addition, in the short-term, both the amount of soybean imports originating in the United States and the per capita consumer spending will affect each other.

\subsection{Outlook}

Although this article analyzes the impact of imported soybean origin countries, 
it only analyzes the amount of money, and does not consider quantity and unit price factors. In addition, this article limits the research object of influence between the import amount and the resident consumer expenditure, but for different eras, the social price index, exchange rate, and consumption concept also have certain differences. All these are the deficiencies of this article. They are also the direction that the author and my colleagues can work hard in the future.

\section{References}

[1] He, L. and Huo, X.X. (2011) Analysis on Import Demand of Japanese Juice Market. International Trade Issues, 11, 116-125.

[2] Ma, S.Z. and Wang, J. (2012) Does China’s Grain Import Trade Have a "Great Country Effect"? Based on the Analysis of Soybean Import Market Forces. Issues in Agricultural Economy, 33, 24-32.

[3] Qin, Y.M. (2012) Analysis of Factors Affecting China's Soybean Import Trade. Nanjing University of Aeronautics and Astronautics, Nanjing.

[4] Wang, Y. (2010) The Impact of RMB Exchange Rate Fluctuation on China's Soybean Import: Taking Sino-U.S. Trade as an Example. Finance and Economics (Academic Edition), No. 3, 34-37.

[5] Chen, Y.F. (2004) China's Food Supply and Demand and Forecast. China Agriculture Press, Beijing.

[6] Chen, W., Marchant, M.A. and Muhammad, A. (2012) China's Soybean Product Imports: An Analysis of Price Effects Using a Production System Approach. China Agricultural Economic Review, 4, 499-513.

https://doi.org/10.1108/17561371211284849 